\title{
ANALISA KEKUATAN STRUKTUR BARGE PADA PROSES LOAD OUT OFFSHORE MODULE (TOP SIDE) DENGAN SPMT
}

\author{
*Habibi Palippui, Sahwan Ramadhan \\ Departemen Teknik Kelautan Universitas Hasanuddin \\ *habibi@unhas.ac.id
}

\begin{abstract}
Abstrak
Salah satu proses yang kritikal ketika fabrikasi offshore yaitu proses transfer offshore module (Top Side) dari atas jetty ke atas transportation barge atau sering disebut Proses Load Out. Salah satu analisa yang dibutuhkan untuk memastikan proses load out berjalan dengan lancar dan aman yaitu analisa kekuatan struktur barge pada saat proses load out tersebut terjadi yaitu dimana dilakukan pengecekan terhadap kekuatan struktur barge apakah mampu menahan beban top side ketika terjadi transfer beban dari atas jetty ke atas transportation barge atau dari tepi barge sampai ke final lokasi. Untuk mendapatkan hasil yang akurat maka digunakan bantuan program komputer atau sering disebut dengan metode elemen hingga (Finite Element Analysis). Adapun software yang digunakan pada analisa ini yaitu StaadPro V8i dengan simulasi percobaan tiga module. Dari hasil analisa diperoleh kesimpulan bahwa simulasi percobaan module tiga memiliki nilai maksimum von misses stress adalah 74,119 N/mm ${ }^{2}$, normal stress adalah $57,765 \mathrm{~N} / \mathrm{mm}^{2}$, dan shear stress adalah 0,02279 $\mathrm{N} / \mathrm{mm}^{2}$, dimana semua nilai tegangan tersebut dibawah tegangan izin atau dibawah batas maksimal yang disyaratkan American Institute of Steel Construction (AISC) sehingga struktur barge tidak perlu diberikan tambahan penguatan baik internal maupun eksternal karena masih aman dan mampu untuk menahan beban top side ketika load. Analisis dengan SPMT berpotensi menjadi patokan dalam dalam menganalisis kekuatan struktrur barge dalam proses load out offshore module (top side).
\end{abstract}

Kata Kunci: Load Out, Top Side, SPMT, Barge, Finite Element.

\begin{abstract}
Abstrct
One of the critical processes when fabricating offshore is the process of transferring the offshore module (Top Side) from the top of the jetty to the transportation barge or often called theProcess Load Out. One of the analyzes needed to ensure the process load out runs smoothly and safely is the analysis of the strength of the barge structure when the load out process occurs, which is checking the strength of the barge structure whether it is able to withstand the load topside when there is load transfer from the top of the jetty to transportation barge or from the edge of the barge to the final location. To get accurate results, the help of computer programs is used or often called the finite element method (Finite Element Analysis). The software used in this analysis is Staad Pro V8i with a three-module simulation experiment. From the analysis it was concluded that the three module simulation simulations have a maximum value of von mises stress is $74.119 \mathrm{~N} / \mathrm{mm}^{2}$, normal stress is $57.765 \mathrm{~N} / \mathrm{mm}^{2}$, and shear stress is $0.02279 \mathrm{~N} \mathrm{~mm}^{2}$, where all stress values are below the maximum limit required by the American Institute of Steel Construction (AISC) so that the barge structure does not need to be given additional reinforcement both internally and externally because it is still safe and able to withstand the topside when loading. Analysis with SPMT has the potential to be a benchmark in analyzing the strength of the barge structure in the process of loading out the offshore module (top side).
\end{abstract}

Keyword: Load Out, Top Side, SPMT, Barge, Finite Element.

\section{PENDAHULAN}

Load out adalah salah satu proses yang terjadi pada saat fabrikasi bangunan lepas pantai. Load out adalah proses pemindahan struktur bangunan lepas pantai (offshore) dari lapangan fabrikasi atau dermaga ke atas copyright is published under Lisensi Creative Commons Atribusi 4.0 Internasional. 
barge dimana barge tersebut akan membawa bangunan offshore ke lokasi instalasi [1] proses load out ada beberapa metode, yaitu:

a. Trailer load out, yaitu proses load out dimana trailer akan bergerak ke bawah struktur, dan sesuai arahan, trailer tersebut akan mengangkat struktur dan bergerak ke atas barge untuk ditempatkan di lokasi final.

b. Skidded load out, yaitu proses load out dimana struktur akan ditempatkan diatas rel baja dan winch akan digunakan untuk menarik atau mendorong struktur ke atas barge dimana skid beam akan digunakan untuk membawa struktur ke final posisi diatas barge.

c. Lifting load out, yaitu proses load out dimana module akan diangkat ke atas deck barge menggunakan crane yang berada di darat atau crane dari laut.

d. Float away load out, yaitu proses load out dimana struktur akan dibangun di atas fasilitas dry dock seperti semi submersible hulls, TLP hulls, FPSO hulls, atau yang lainnya.

Banyak hal yang menjadi pertimbangan ketika memilih metode load out yang akan digunakan seperti berat struktur, bentuk dari struktur offshore, kondisi [2] [3] yard tempat membangun struktur tersebut ataupun yang berhubungan dengan sisi komersial. Saat ini, metode load out dengan menggunakan trailer-lah yang paling sering digunakan karena memiliki banyak kelebihan dibandingkan metode yang lain seperti dapat memindahkan [4] struktur yang memiliki ukuran atau berat yang besar, proses load out dapat berjalan dengan cepat atau dapat menjaga elevasi struktur tetap nol ketika terjadi proses [5] pemindahan struktur dari atau jetty ke atas barge yang ditampilkan seperti pada gambar berikut.

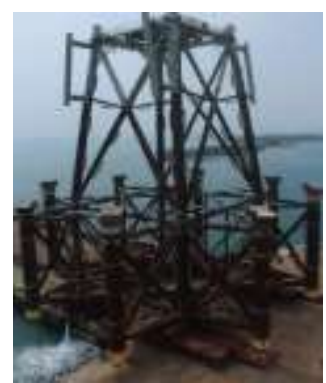

Gambar 1. Proses Load Out dengan Trailer (SPMT) [6]

Hal yang paling penting ketika proses load out menggunakan trailer (SPMT) yaitu kemampuan struktur barge menahan beban total dari trailer dan bangunan offshore ketika terjadi proses pemindahan beban dari atas jetty ke atas barge [5] sehingga diperlukan suatu analisa yang tepat untuk mengecek kekuatan barge tersebut. Maka digunakanlah perhitungan dengan metode elemen hingga atau Finite Element Analysis dengan bantuan software Staad Pro.

\section{METODE}

SPMT (Self Proppeled Modular Transporter) adalah salah satu jenis alat yang digunakan untuk load out offshore module. SPMT akan bergerak ke bawah skid frame topside, setelah dipastikan lokasi SPMT sesuai dengan design dari engineering, maka SPMT akan mengangkat serta membawa Top side tersebut ke lokasi final di atas barge. Konfigurasi SPMT yang digunakan untuk loada out top side yaitu side by side dengan total SPMT adalah 24 axle.

\subsection{Data Muatan}

Barge yang digunakan untuk load out top side adalah Kreuz 283 dimana barge ini bertipe flat top barge. Hull dari Kreuz 283 di bagi menjadi 7 transversal bulkhead dan 3 longitudinal bulkhead dengan 32 ballast compartment. Dimensi utama barge Kreuz 283 dapat dilihat pada Table 1.

Table 1. Dimensi Utama Barge Kreuz 283 dan muatannya

\begin{tabular}{lll}
\hline No & Description & Data \\
\hline 1 & Panjang Keseluruhan ( LOA ) & 282 Feet \\
2 & Lebar & 90 Feet \\
3 & Tinggi & 18 Feet \\
\hline
\end{tabular}

copyright is published under Lisensi Creative Commons Atribusi 4.0 Internasional. 


\begin{tabular}{lll}
\hline 4 & Deck Loading & $15 \mathrm{~T} / \mathrm{m} 2$ \\
5 & Jumlah Tank & 32 anks Ballastable \\
6 & Total berat top side & 687,45 Ton \\
7 & Skid frame & 38,46 Ton \\
8 & SPMT & 87,3 Ton \\
\hline
\end{tabular}

\subsection{Analisa Studi Kasus}

Selama proses load out top side terdapat 3 load case yang digunakan dalam analisa. Adapun detail 3 load case tersebut dapat dilihat pada table 3 dan detail gambar proses load out diperlihatkan pada gambar 2 sampai dengan. gambar 4.

Table 2. Detail Load Case pada Proses Load Out Top Side

\begin{tabular}{lll}
\hline No & Description & Data \\
\hline 1 & Load case 1 & Berat mati barge + Berat Top Side 2 axle line SPMT diatas barge ) \\
2 & Load case 2 & Berat mati barge + Berat Top Side (10 axle line SPMT diatas barge ) \\
3 & Load case 3 & Berat mati barge + Berat Top Side (final posisi diatas barge ) \\
\hline
\end{tabular}

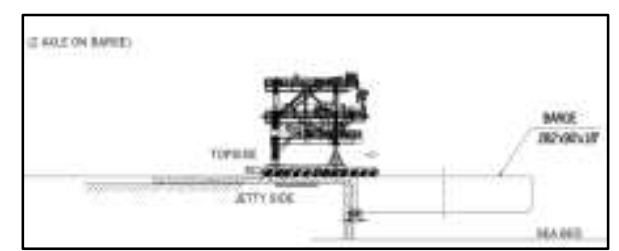

Gambar 2. Detail Load Case 1

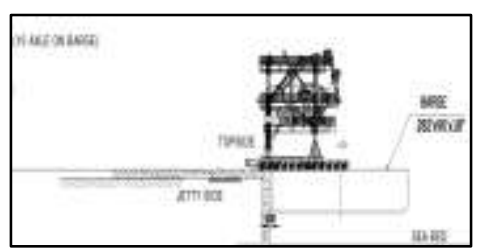

Gambar 3. Detail Load Case 2

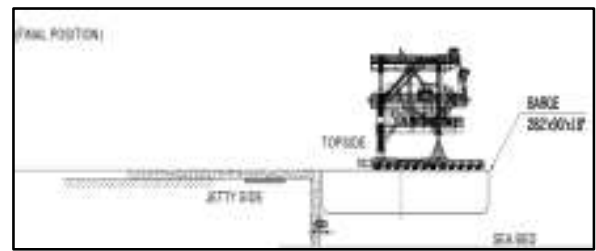

Gambar 4. Detail Load Case 3

\subsection{Model Struktur}

Finite element computation program dari Staad Pro digunakan untuk menghitung tegangan dari struktur barge. Konstruksi dan profil struktur dari barge Kreuz 283 di modelkan dan dianalisa dengan menggunakan software Staad Pro dengan tampilan seperti pada Gambar 5

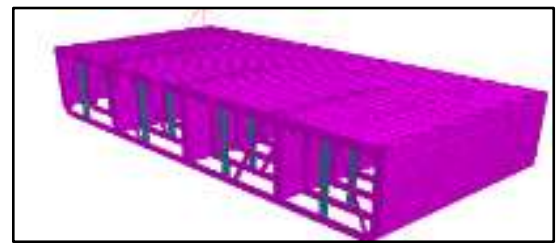

Gambar 5. 3D model dari software Staad Pro.

\subsection{Material Properti dan Desain Beban}

Material yang digunakan dalam analisa ini yaitu baja dengan spesifikasi Yield Strength (Fy) 234 Mpa, young modulus (E) $210000 \mathrm{Mpa}$, poisson ratio (v) 0.3 , Density $7850 \mathrm{~kg} / \mathrm{m}^{3}$, beban mati (DL) yaitu beban sendiri dari barge, beban hidup (LL) yaitu jumlah axle line dari SPMT yang berada diatas barge dan beban kombinasi (CL) diperoleh dari DL + LL. 


\section{HASIL DAN PEMBAHASAN}

\subsection{Pemodelan Struktur Barge}

Finite element computation program dari Staad Pro V8i digunakan untuk menghasilkan tegangan dari struktur barge. Pemodelan construction dan profil barge Kreuz 283 menggunakan software Staad Pro. Penampang goemetry dari barge Kreuz 283 yang telah di-runing ditampilkan pada Gambar 5.

\subsection{Pemberian Beban}

\subsubsection{Beban Mati ( DL ) dan Kombinasi}

Beban mati dan kombinasi dihitung secara otomatis oleh Staad Pro pada saat di-running sperti pada tampilan gambar berikut.

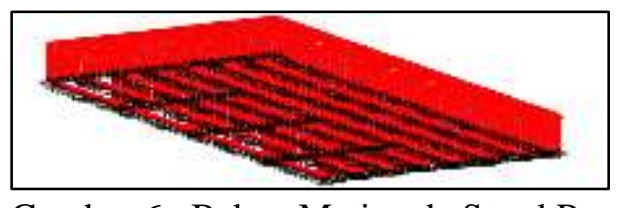

Gambar 6. Beban Mati pada Staad Pro

\subsubsection{Beban Hidup ( LL )}

Load Case 1

Maksimum ground bearing pressure dari top side ke SPMT $=6,83 \mathrm{Ton} / \mathrm{m}^{2}$. Point load akan disebarkan ke area barge dari SPMT sesuai dengan load case 1 ( 2 axle line SPMT diatas barge $)=1.5 \mathrm{~m} \mathrm{x} 6.3 \mathrm{~m}=9.45 \mathrm{~m}^{2}$. Adapun proses running program load case 1 dapat dilihat pada gambar di bawah.

Load Case 2

Maksimum ground bearing pressure dari top side ke SPMT $=6,83 \mathrm{Ton} / \mathrm{m}^{2}$. Point load akan disebarkan ke area barge dari SPMT sesuai dengan load case $2(10$ axle line SPMT diatas barge $)=13.5 \mathrm{~m} \times 6.3 \mathrm{~m}=85.05$ $\mathrm{m}^{2}$. Adapun proses running program load case 2 dapat dilihat pada gambar di bawah.

Load Case 3

Maksimum ground bearing pressure dari top side ke SPMT $=6,83 \mathrm{Ton} / \mathrm{m}^{2}$. Point load akan disebarkan ke area barge dari SPMT sesuai dengan load case 3 (12 axle line SPMT diatas barge di final posisi) $=16.5 \mathrm{~m} \mathrm{x}$ $6.3 \mathrm{~m}=103.95 \mathrm{~m}^{2}$. Adapun proses running program load case 3 dapat dilihat pada gambar di bawah.

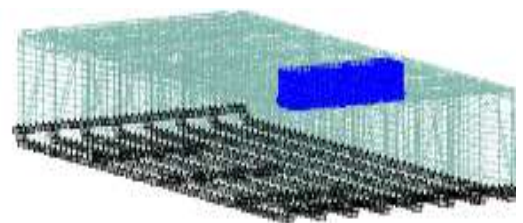

Gambar 7. Beban Hidup dari Load Case 1.

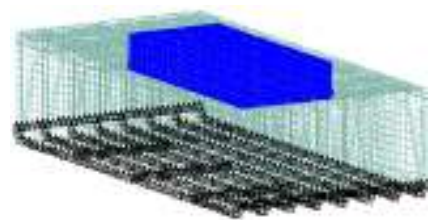

Gambar 8. Beban Hidup dari Load Case 2

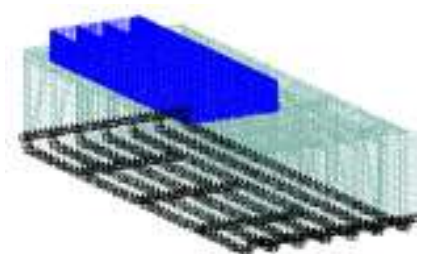

Gambar 9. Beban Hidup dari Load Case 3

\subsection{Hasil Analisa}

\section{Load Case 1}

Hasil running load case 1 pada program dapat dilihat pada Gambar 11. Berdasarkan hasil analisa load case 1 maka diperoleh maksimal von misses stress yang terjadi pada struktur barge adalah $33.734 \mathrm{~N} / \mathrm{mm}^{2}$. Jika nilai von misses stress tersebut dibandingkan dengan allowable stress material $175.5 \mathrm{~N} / \mathrm{mm}^{2}$, maka diperoleh nilai unity check sebesar 0.192 dibawah batas maksimal yang disyaratkan AISC. 


\section{Load Case 2}

Hasil running load case 2 pada program dapat dilihat pada Gambar 12. Berdasarkan hasil analisa load case 2 maka diperoleh maksimal von misses stress yang terjadi pada struktur barge adalah $74.119 \mathrm{~N} / \mathrm{mm}^{2}$. Jika nilai von misses stress tersebut dibandingkan dengan allowable stress material $175.5 \mathrm{~N} / \mathrm{mm}^{2}$, maka diperoleh nilai unity check sebesar 0.422 lebih kecil dari 1 atau masih dibawah batas maksimal yang disyaratkan AISC.

Load Case 3

Hasil running load case 3 pada program dapat dilihat pada Gambar 13. Berdasarkan hasil analisa load case 3 maka diperoleh maksimal von misses stress yang terjadi pada struktur barge adalah $69.930 \mathrm{~N} / \mathrm{mm}^{2}$. Jika nilai von misses stress tersebut dibandingkan dengan allowable stress material $175.5 \mathrm{~N} / \mathrm{mm}^{2}$, maka diperoleh nilai unity check sebesar 0.398 lebih kecil dari 1 atau masih dibawah batas maksimal yang disyaratkan AISC.

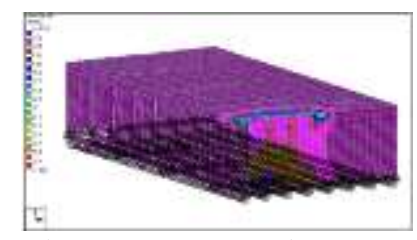

Gambar 10. Deck Strength Contour Load Case 1

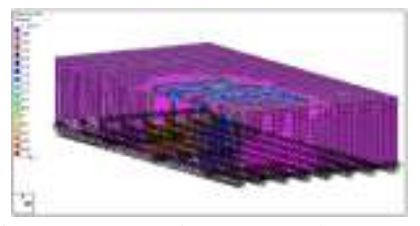

Gambar 11. Deck Strength Contour Load Case 2

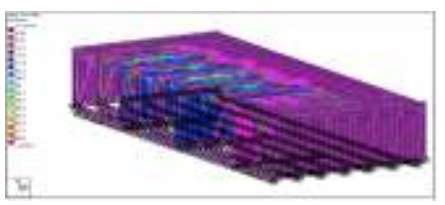

Gambar 13. Deck Strength Contour Load Case 3

Hasil analisa 3 load case pada struktur barge ditampilkan pada Tabel 3.

Table 3. Hasil Analisa Kekuatan Struktur Barge

\begin{tabular}{|c|c|c|c|c|c|c|c|c|c|c|c|c|}
\hline & \multicolumn{4}{|c|}{ Shear stress } & \multicolumn{4}{|c|}{ Normal Stress } & \multicolumn{4}{|c|}{ Von Misses Stress } \\
\hline & \multicolumn{4}{|c|}{$\mathrm{N} / \mathrm{mm} 2$} & \multicolumn{4}{|c|}{$\mathrm{N} / \mathrm{mm} 2$} & \multicolumn{4}{|c|}{$\mathrm{N} / \mathrm{mm} 2$} \\
\hline & $\operatorname{Max}$ & UC & $\begin{array}{c}\text { Allow } \\
\text { Stress } \\
(0.4 \text { x Fy })\end{array}$ & Status & Max & UC & $\begin{array}{l}\text { Allow Stress } \\
\qquad(0.6 \times \text { Fy })\end{array}$ & Status & Max & UC & $\begin{array}{c}\text { Allow } \\
\text { Stress } \\
(0.75 \times \text { Fy })\end{array}$ & Status \\
\hline LC1 & 0.93 & 0.009 & 93.6 & Pass & 24.197 & 0.172 & 140.4 & Pass & 33.734 & 0.192 & 175.5 & Pass \\
\hline LC2 & 1.552 & 0.016 & 93.6 & Pass & 57.765 & 0.411 & 140.4 & Pass & 74.119 & 0.422 & 175.5 & Pass \\
\hline LC3 & 2.135 & 0.022 & 93.6 & Pass & 56.665 & 0.403 & 140.4 & Pass & 69.93 & 0.398 & 175.5 & Pass \\
\hline
\end{tabular}

\section{KESIMPULAN}

Berdasarkan hasil finite element analysis yang dilakukan untuk mengecek kekuatan struktur barge maka diperoleh nilai maksimal von misses stress $=74,119 \mathrm{~N} / \mathrm{mm}^{2}(\mathrm{UC}=0,422<1)$ dan maksimal normal stress $=57,765 \mathrm{~N} / \mathrm{mm}^{2}(\mathrm{UC}=0,411<1)$ sementara nilai shear stress sangat kecil yaitu sebesar $2,135 \mathrm{~N} / \mathrm{mm}^{2}$ (UC $=0,022<1)$. Maximum stress terjadi pada load case 2 dimana ground bearing pressure dari SPMT sebesar $6.83 \mathrm{Ton} / \mathrm{m}^{2}$ dengan luas area diatas barge sebesar $85.05 \mathrm{~m}^{2}$. Nilai stress yang terjadi masih berada dibawah tegangan izin atau batas maksimal yang diisyaratkan oleh AISC sehingga tidak perlu dilakukan penguatan pada barge baik itu secara internal maupun secara external.

\section{DAFTAR PUSTAKA}

[1] Chakrabarti S K 2005 Handbook of Offshore Engineering vol I

[2] Gerwick B C 2000 Construction of Offshore Second Edition

[3] Version F P S 2004 Engineering Data Book

[4] Young W C and Budynas R G Roark's Formulas for Stress and Strain

[5] Series L C A L 2014 Offshore Crane Technology Liebherr CAL Series

[6] T Stolarski, Y Nakasone S Y 2007 Engineering Analysis with ANSYS Software Dep. Mech. Eng. Sch. Eng. Des. Brunel Univ. 